\title{
Recycled Waste Glass [WG] in Concrete
}

\author{
KIM Ibrahim* \\ Construction Engineering Dept., College of Engineering at Qunfudha, Umm-Al-Qura University- KSA on Sabbatical leave from higher Institute of Engineering \\ and Technology of Kafr-EL-Shiekh, Egypt
}

*Corresponding author: KIM Ibrahim, Construction Engineering Dept., College of Engineering at Qunfudha, Umm-Al-Qura University- KSA on Sabbatical leave from higher Institute of Engineering and Technology of Kafr-EL-Shiekh, Egypt

Received Date: June 03, 2020

Published Date: July 06, 2020

\begin{abstract}
In this study, WG was used as partial substitution of basalt (coarse aggregate), with $0 \%, 5 \%, 10 \%, 15 \%, 20 \%, 25 \%, 30 \%, 35 \%, 40 \%, 45 \%$ and $50 \%$ ratios by weight of basalt. Some mechanical and other concrete properties have been investigated at both hardened and fresh stages. The investigational results that were taken from the tested specimens illustrated that with WG using as a coarse aggregate occurred a loss in a slump, density, and water absorption. It also resulted in the enhancement of the strengths of concrete [compression and tension] until a $25 \%$ ratio of substitution by weight. Test results registered that with WG content increase, the strengths gradually increase up to a given limit, and then beyond which they gradually decrease. The maximum influence reached a $25 \%$ substitution ratio. At this percentage, the strengths [tension and compression] increasing were approximately $15 \%$ and $14 \%$ with relating to control concrete [0\% WG] respectively.
\end{abstract}

Keywords: Concrete; Waste glass; Coarse aggregate; Compressive strength

\section{Introduction}

Concrete comprises three boss constituents (aggregate, cement, and water). The proportion and type of ingredients change the last item (concrete) properties [1]. The waste disposal problem was caused by non-decomposing waste materials, thus contributing to the environmental crisis [2]. Various manufacturing waste substances as tiles waste aggregates from the destruction of buildings, slag, fly ash, etc., have been attempted as extra material in concrete [3]. For many decades' efforts had been devoted to using WG in concrete [4-5]. Many investigators studied WG usage in plain concrete [6-21]. Glass has been indispensable to man's life due to its properties such as flexibility, to take any shape with ease, polished surface, resistance to abrasion, safety, and durability. Utilizing WG in concrete has obtained far more attention in parallel to environmental awareness. While Utilizing WG in concrete as aggregate enhances some of the concrete characteristics, it also negatively influences some others. While the quantity of the WG combined within the concrete, reduces the compressive strength because adherence cannot be completed fully between the WG and paste of cement. Additionally, as the WG content increases, the concrete toughness decreases, because glass fails to absorb water and consequently stops many the relief of energy through the cement hydration [22]. Studies in a WG have concluded an unwelcome reaction between waste glass, in which active silica is being, and cement which possesses a large quantity of alkali oxide, named alkali-silica reaction (ASR), consequently expansion grows to the detriment of the sustainability of the concrete $[23,24]$. Another study indicates that when the quantity of WG rises, the voids in concrete grow owing to the delicate appearance of the waste glass grains and its lower compactness, so the strength of concrete drops [25]. During utilizing coarse waste glass particles as aggregate, the concrete strength decreases, because waste glass aggregates have considerably bad shape, poor surface properties, and high friability [26]. This investigation tried to explore the WG utilizing impact in concrete. 


\section{Materials}

\section{Cement}

The cement utilized in this research was locally sourced, conforming to the ESS 2421/2005 [27]. The cement mechanical Table 1: Cement properties.

\begin{tabular}{|c|c|}
\hline Results & Properties \\
\hline 0.95 & Soundness (Le Chatelier) [mm] \\
\hline 96 & Initial setting time [min] \\
\hline 157 & Finial setting time [min] \\
\hline 22.2 & Compressive strength $[\mathrm{MPa}] 3 \mathrm{days}$ \\
\hline 47.5 & Compressive strength[(MPa] 28days \\
\hline
\end{tabular}

Table 2: Cement chemical composition.

\begin{tabular}{|c|c|}
\hline Composition & \% By Mass \\
\hline Silica $\left(\mathrm{SiO}_{2}\right)$ & 21.19 \\
\hline Alumina $\left(\mathrm{Al}_{2} \mathrm{O}_{3}\right)$ & 4.72 \\
\hline Iron oxide $\left(\mathrm{Fe}_{2} \mathrm{O}_{3}\right)$ & 3.05 \\
\hline Calcium oxide $(\mathrm{CaO})$ & 61.94 \\
\hline Magnesium oxide $(\mathrm{MgO})$ & 2.62 \\
\hline Sodium oxide $\left(\mathrm{Na}_{2} \mathrm{O}\right)$ & 0.28 \\
\hline Potassium oxide $\left(\mathrm{K}_{2} \mathrm{O}\right)$ & 0.84 \\
\hline Sulphur trioxide $\left(\mathrm{SO}_{3}\right)$ & 3.92 \\
\hline
\end{tabular}

\section{Aggregate}

In this exploratory work, the aggregates [sand+ basalt] used of aggregate [coarse and fine], were investigated by the ESS 1109/2002 [28] and the outcomes are exhibited in Table 3. properties were measured by laboratory tests that indicated its reasonableness for concrete works. In this investigation, chemical composition and mechanical properties of cement are exhibited in Table 1 \& Table 2 . were local. The basalt has a $25 \mathrm{~mm}$ maximum grain size. Properties

Table 3: Properties of sand, basalt, and WG.

\begin{tabular}{|c|c|c|c|}
\hline Waste Glass & Basalt & Sand & Property \\
\hline 2.31 & 2.66 & 2.68 & Specific weight \\
\hline 1.39 & 1.68 & 1.72 & Density $\left[\mathrm{t} / \mathrm{m}^{3}\right]$ \\
\hline 0.2 & 0.4 & 1.23 & Water absorption $\%$ \\
\hline 27.5 & 24.2 & - & Abrasion value $\%$ \\
\hline 31.7 & 28.5 & - & Impact value $\%$ \\
\hline
\end{tabular}

\section{Waste glass}

WG was used as a coarse aggregate in concrete in this study. Figure 1 illustrates the WG particle shape. It was brought from a glass factory wastes then crushed in the apparatus of aggregate Table 4: Waste glass chemical composition.

\begin{tabular}{|c|c|}
\hline Composition & \% by Mass \\
\hline Silica $\left(\mathrm{SiO}_{2}\right)$ & 70.52 \\
\hline Alumina $\left(\mathrm{Al}_{2} \mathrm{O}_{3}\right)$ & 0.62 \\
\hline Iron oxide $\left(\mathrm{Fe}_{2} \mathrm{O}_{3}\right)$ & 0.71 \\
\hline Calcium oxide $(\mathrm{CaO})$ & 9.82 \\
\hline Magnesium oxide $(\mathrm{MgO})$ & 3.31 \\
\hline Sodium oxide $\left(\mathrm{Na}_{2} \mathrm{O}\right)$ & 12.95 \\
\hline Potassium oxide $\left(\mathrm{K}_{2} \mathrm{O}\right)$ & 0.28 \\
\hline Sulphur trioxide $\left(\mathrm{SO}_{3}\right)$ & --- \\
\hline
\end{tabular}




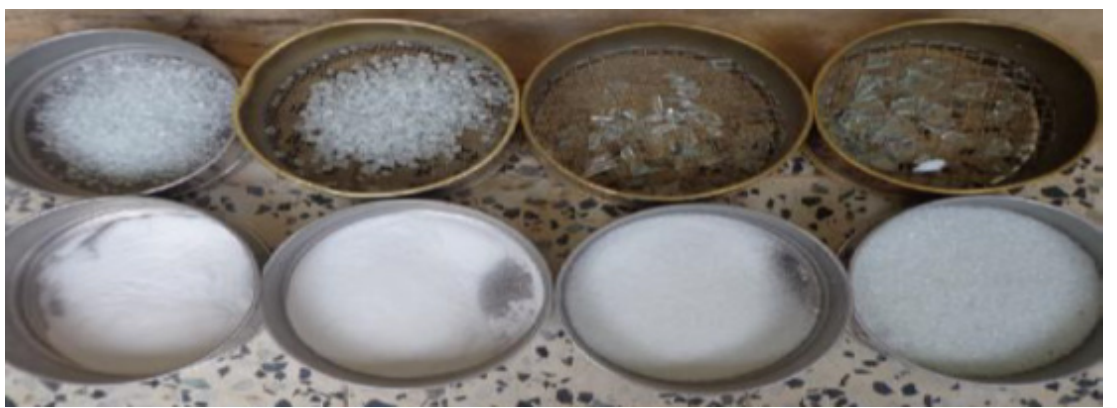

Figure 1: Particles shape of coarse WG after sieve analysis.

Table 5: Sieve analysis data for coarse waste glass.

\begin{tabular}{|c|c|}
\hline \% Passing & Sieve Size (mm) \\
\hline 100 & 25 \\
\hline 90 & 19 \\
\hline 72 & 14 \\
\hline 30 & 9.5 \\
\hline 2 & 4.75 \\
\hline 0 & 2.36 \\
\hline 0 & 1.18 \\
\hline 0 & 0.6 \\
\hline 0 & 0.3 \\
\hline 0 & 0.15 \\
\hline
\end{tabular}

\section{Mixing water}

For mixing, drinking water was used.

\section{Super plasticizers}

In concrete mixture, the super plasticizer is viewed as high water reducing tool. The super plasticizer used was from SIKA Company.

\section{Experimental Procedure}

\section{Mixture proportioning}

In this investigation, two sorts of concrete mixes were created. The first is the control concrete mix consisted of sand $\left(594 \mathrm{~kg} / \mathrm{m}^{3}\right)$, basalt $\left(1188 \mathrm{~kg} / \mathrm{m}^{3}\right)$, cement $(400 \mathrm{~kg} / \mathrm{m} 3)$, and water $(200 \mathrm{~kg} /$ $\mathrm{m} 3$ ). The second concrete mixes were produced from WG coarse aggregates of $5 \%, 10 \%, 15 \%, 20 \%, 25 \%, 30 \%, 35 \%, 40 \%, 45 \%$ and $50 \%$ ratios as partial substitution of coarse aggregate and with the equal masses of sand, cement, and water of the control mix. Furthermore, a super plasticizer was utilized per m3 to keep the slump values goes between [6-11] cm. Both of the two concrete mixes types were cured for 28 days. Table 6 shows the concrete mixes proportion.

\section{Casting and curing of test specimens}

As listed by B.S.1881:1952 [29], cast, compaction, and curing were fulfilled. Tests were done on fresh concretes to define the slump values. For the compressive strength determination at 28 days, three cubes ( $15 \mathrm{~cm}$ length) were cast for every concrete mix, also for indirect tensile strength, three cylinders $(30 \mathrm{~cm}$ length and $15 \mathrm{~cm}$ diameter) was cast.

\section{Testing of specimens}

Slump test: Achieved by BS 12350-2:2009 [30], this test was accomplished on fresh concretes to define the concrete workability.

Dry density: Just before the compression test, for totally concrete mixes, the dry density was calculated as stated by B.S.1881:1952 [29].

Water absorption test: Accomplished by B.S.1881:1952 [29]. The cubes dry weight was estimated after eliminating from molds. Moreover, the cube's mass was measured after submersing in a water tank for curing 28 days of age. Then for every concrete cube, the water absorption ratio was estimated.

Compressive strength: For each mix, concrete cubes with $15 \mathrm{~cm}$ length were manufactured and cured in water until test age by ESS 1658 /2006 [31].

Splitting tensile strength: For each mix, concrete cylinders with300 $\mathrm{mm}$ height and $150 \mathrm{~mm}$ diameter were manufactured and cured in water until test age by ESS 1658 /2006 [31].

\section{Results and Discussions}

\section{Slump test}

The results of the slump tests are given in Table 6. Figure 2 illustrates the decreasing rates in the slump. The slump values were defined to be $10,9.6,9.3,8.9,8.7,8.2,7.9,7.7,7.6,7.3$, and 
7.1 for specimens manufactured from $0 \%, 5 \%, 10 \%, 15 \%, 20 \%$ ,25,30\%,35\%,40\%,45\%, and 50\%WG, respectively. The results illustrate the inclination of the slump to lower as the WG ratio rises. This drop in the slump values can be related to the bad geometry of the WG shape, which results in lesser fluidity of the mixes as well as the decrease of fineness modulus. Despite the drop in the slump

Table 6: Concrete mixes proportion.

\begin{tabular}{|c|c|c|c|c|c|c|c|}
\hline Super Plasticizer kg/m3 & Sand $\mathrm{kg} / \mathrm{m}^{3}$ & Basalt kg/m ${ }^{3}$ & Water $\mathrm{kg} / \mathrm{m}^{3}$ & Cement kg/m³ & Waste Glass kg/m³ & Waste Glass \% & Mix No. \\
\hline 4 & 594 & 1188 & 200 & 400 & 0 & $0 \%$ & 1 \\
\hline 4 & 594 & 1128.6 & 200 & 400 & 59.4 & $5 \%$ & 2 \\
\hline 4 & 594 & 1069.2 & 200 & 400 & 118.8 & $10 \%$ & 3 \\
\hline 4 & 594 & 1009.8 & 200 & 400 & 178.2 & $15 \%$ & 4 \\
\hline 4 & 594 & 950.4 & 200 & 400 & 237.6 & $20 \%$ & 5 \\
\hline 4 & 594 & 891 & 200 & 400 & 297 & $25 \%$ & 6 \\
\hline 4 & 594 & 831.6 & 200 & 400 & 356.4 & $30 \%$ & 7 \\
\hline 4 & 594 & 772.2 & 200 & 400 & 415.8 & $35 \%$ & 8 \\
\hline 4 & 594 & 712.8 & 200 & 400 & 475.2 & $40 \%$ & 9 \\
\hline 4 & 594 & 653.4 & 200 & 400 & 534.6 & $45 \%$ & 10 \\
\hline 4 & 594 & 594 & 200 & 400 & 594 & $50 \%$ & 11 \\
\hline
\end{tabular}

Table 7: Slump results.

\begin{tabular}{|c|c|}
\hline WG content $\%$ & Slump [cm] \\
\hline $0 \%$ & $10($ control) \\
\hline $5 \%$ & $9.8(-2 \%)$ \\
\hline $10 \%$ & $9.6(-4 \%)$ \\
\hline $15 \%$ & $9.5(-5 \%)$ \\
\hline $20 \%$ & $9.4(-6 \%)$ \\
\hline $25 \%$ & $9.2(-8 \%)$ \\
\hline $30 \%$ & $8.9(-11 \%)$ \\
\hline $35 \%$ & $8.7(-13 \%)$ \\
\hline $40 \%$ & $8.6(-14 \%)$ \\
\hline $45 \%$ & $8.5(-15 \%)$ \\
\hline $50 \%$ & $8.5(-15 \%)$ \\
\hline
\end{tabular}

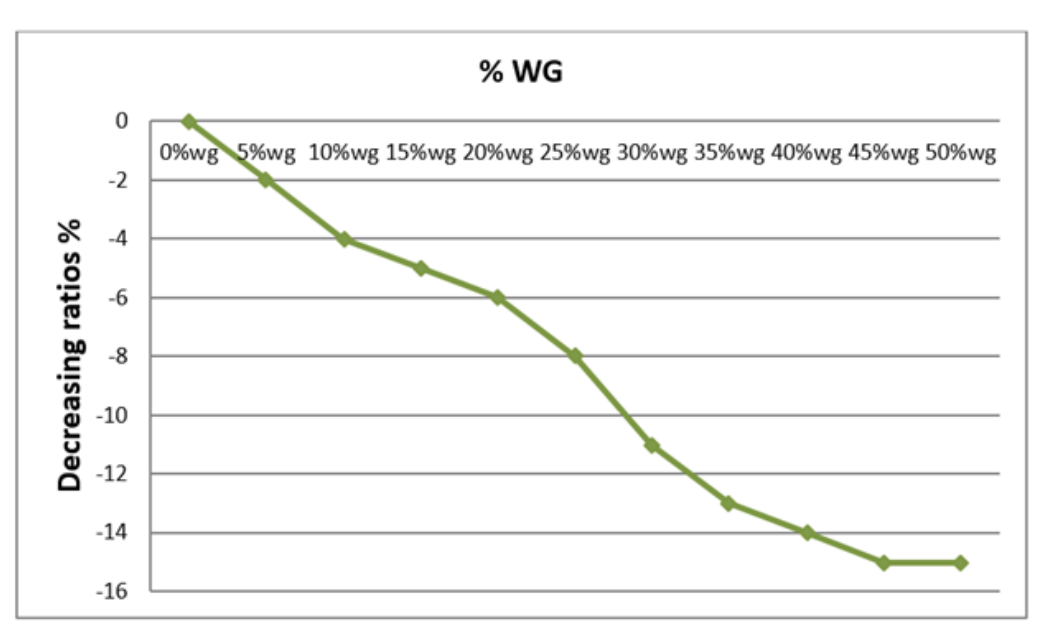

Figure 2: Decreasing ratios in the slump. 


\section{Dry density}

Table 8 displays the dry densities of WG concrete mixes at 28 days of curing ages. The decreasing ratios in dry densities of specimens made of $5 \%, 10 \%, 15 \%, 20 \%, 25 \%, 30 \%, 35 \%, 40 \%, 45 \%$,and $50 \%$ waste glass compared to control concrete[0\%WG] are $0.25 \%$, $0.63 \%, 0.96 \%, 1.21 \%, 1.42 \%, 1.88 \% \quad, 2.26 \%, 2.84 \%, 3.31 \% \quad$ and $3.85 \%$, respectively, as presented in Figure 3. The decrease in the dry density of the waste glass concrete mixes can be attributed to the specific gravity of the WG, which is lower than that of the basalt. Similar outcomes were recorded by Canbaz \& Topcu [10], which established the conclusion that the concrete unit weight with WG is lesser than that without WG. Despite the reduction in the dry density values of WG concrete mixes, they are yet comparable to the control mixes $[0 \% \mathrm{WG}]$.

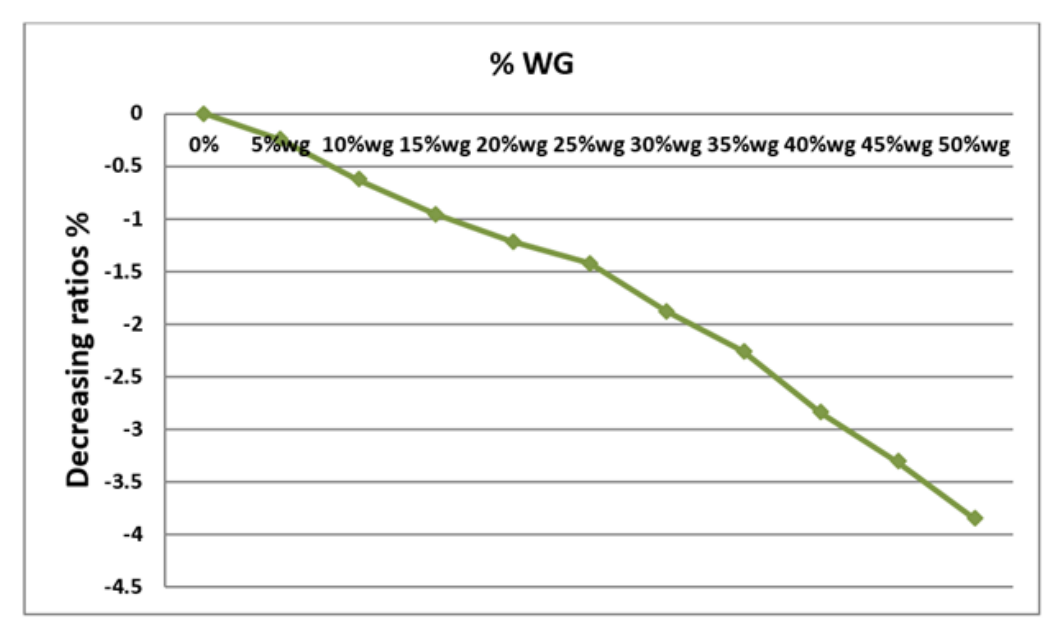

Figure 3: Decreasing ratios in the density.

Table 8: Dry density results.

\begin{tabular}{|c|c|c|}
\hline \% of dry Density Reduction & Dry Density $\left[\mathrm{kg} / \mathbf{m}^{3}\right]$ & WG Content $\%$ \\
\hline Control & 2390 & $0 \%$ \\
\hline $0.25 \%-$ & 2384 & $10 \%$ \\
\hline $0.63 \%-$ & 2375 & $15 \%$ \\
\hline $0.96 \%-$ & 2367 & $20 \%$ \\
\hline $1.21 \%-$ & 2361 & $25 \%$ \\
\hline $1.42 \%-$ & 2356 & $30 \%$ \\
\hline $1.88 \%-$ & 2345 & $35 \%$ \\
\hline $2.26 \%-$ & 2336 & $40 \%$ \\
\hline $2.84 \%-$ & 2322 & $45 \%$ \\
\hline $3.31 \%-$ & 2311 & $50 \%$ \\
\hline $3.85 \%-$ & 2298 & \\
\hline
\end{tabular}

\section{Water absorption}

Table 9 represents the level of water absorption ratio for all mixes. Figure 4 shows that the rate of water absorption decreased with WG content increasing, and this is maybe because the glass water absorption ratio is almost zero. Same results were stated by Table 9: Water absorption results.

\begin{tabular}{|c|c|}
\hline Water Absorption \% & WG Content \% \\
\hline 1.13 & $0 \%$ \\
\hline 1.05 & $5 \%$ \\
\hline 0.95 & $10 \%$ \\
\hline 0.92 & $15 \%$ \\
\hline 0.85 & $20 \%$ \\
\hline
\end{tabular}

Muzamil Liaqat, et al., [3], they verified that the WG concrete water absorption ratio is lesser than of concrete without $W G$, also reported that with increasing WG coarse aggregate ratio the concrete water absorption ratio decreased. In this research, the lowest value of the water absorption ratio was found at $50 \%$ WG content. 


\begin{tabular}{|c|c|}
\hline 0.82 & $25 \%$ \\
\hline 0.8 & $30 \%$ \\
\hline 0.65 & $35 \%$ \\
\hline 0.6 & $40 \%$ \\
\hline 0.52 & $45 \%$ \\
\hline 0.5 & $50 \%$ \\
\hline
\end{tabular}

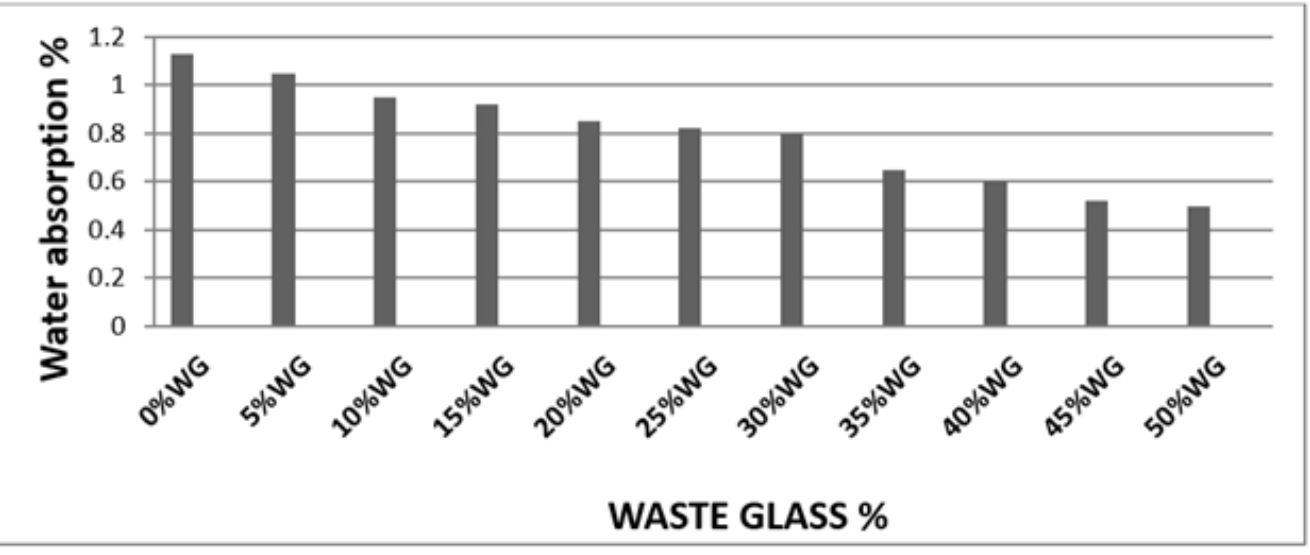

Figure 4: Water absorption values.

\section{Compressive strength}

The compressive strength test results of control and recycled glass concrete mixes at age 28 days are summarized in Table 10. Each given value is the average of three measurements. It is evident from Table 10 that the usage of recycled glass waste as a basalt replacement until a $25 \%$ replacement ratio rises the compressive strength of the concrete mixes related to the control mixture $[0 \% \mathrm{WG}]$, the increase was $[6.72 \%, 8.77 \%, 10.23 \%, 11.46 \%$,
13.65\%] respectively. Also, it can be noticed from Figure 5 that as the WG content increases from $25 \%$ to $50 \%$, the compressive strength decreased gradually, and The reduction of concrete compressive strength was [about 18\%] at 50\% ratio related with the control mix. The same results were stated by Olomo Rachael 0 , et al., [2]. They announced that with increasing waste glass coarse aggregate ratio until $25 \%$, the concrete compressive strength increased then decreased after this value. This result agrees with the obtained results in this investigation.

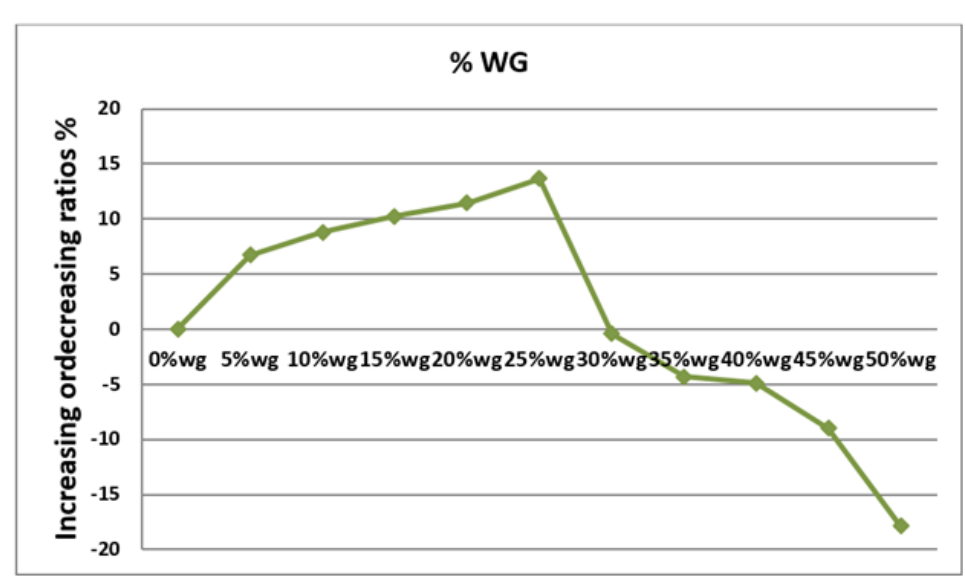

Figure 5: the compressive strength Increasing and decreasing ratios.

Table 10: Concrete compressive strength [MPa] at 28 days.

Compressive Strength [MPa]

WG Content \%

\begin{tabular}{|c|c|}
\hline Compressive Strength [MPa] & WG Content \% \\
\hline $34.2($ control) & $0 \%$ \\
\hline $36.5(+6.72 \%)$ & $5 \%$ \\
\hline
\end{tabular}




\begin{tabular}{|c|l|}
\hline $37.2(+8.77 \%)$ & $10 \%$ \\
\hline $37.7(+10.23 \%)$ & $15 \%$ \\
\hline $38.12(+11.46 \%)$ & $20 \%$ \\
\hline $38.87(+13.65 \%)$ & $25 \%$ \\
\hline $34.06(-0.41 \%)$ & $30 \%$ \\
\hline $32.72(-4.33 \%)$ & $35 \%$ \\
\hline $32.53(-4.88 \%)$ & $40 \%$ \\
\hline $31.12(-9.00 \%)$ & $45 \%$ \\
\hline $28.09(-17.86 \%)$ & $50 \%$ \\
\hline
\end{tabular}

The calculated indirect tensile strengths at age 28 days are displayed in Table 11. Every value is the mean of three measures. Figure 6 registers that the indirect tensile strength leads to an increment with the rise in the proportion of recycled WG replacement in the concrete mix until a $25 \%$ ratio, correlated to the control mix. According to the test results, the 28 days indirect tensile strength values are observed to increase by [9.62\%, $10.04 \%$, $11.3 \%, 12.55 \%, 14.64 \%$ ] for replacement ratios of $5 \%, 10 \%$,
$15 \%, 20 \%$, and 25\%, respectively. These outcomes agree with Vikash Agrawal, et al., [32], who revealed that for 5\% reused glass substitution, the indirect tensile strength of recycled glass concrete increased by $4 \%$ at age 28 days. Likewise, it very well may be seen from Table 11 and Figure 6 that as the WG content increases from $25 \%$ to $50 \%$, the indirect tensile strength decreased gradually, and the reduction of concrete indirect tensile strength was about $21 \%$ at $50 \%$ ratio correlated to the control mix.

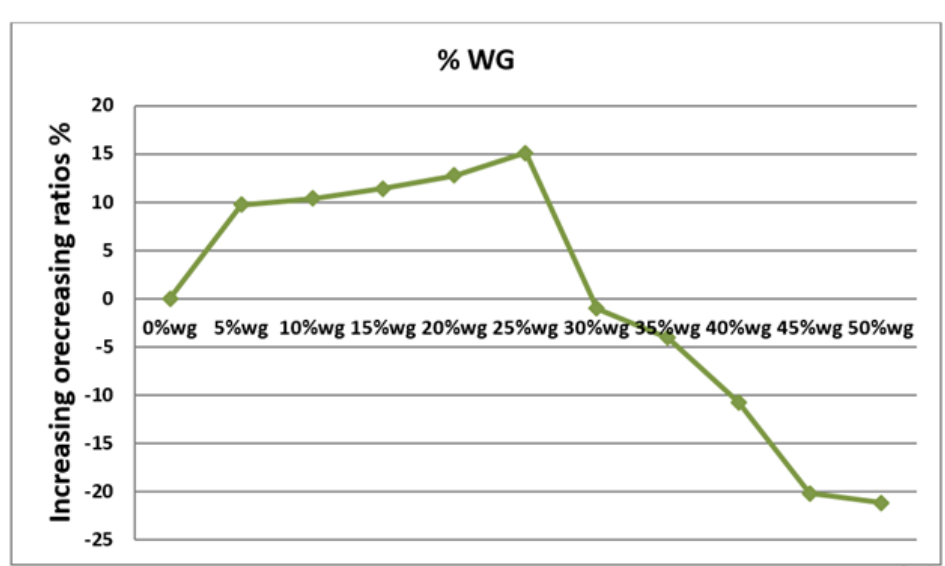

Figure 6: Increasing and decreasing ratios in the tensile strength.

Table 11: Tensile strength [MPa] of concrete after 28 days.

\begin{tabular}{|c|c|}
\hline Tensile Strength [MPa] & WG Content \% \\
\hline $2.98($ control) & $0 \%$ \\
\hline $3.27(+9.73 \%)$ & $5 \%$ \\
\hline $3.29(+10.4 \%)$ & $10 \%$ \\
\hline $3.32(+11.41 \%)$ & $15 \%$ \\
\hline $3.36(+12.75 \%)$ & $20 \%$ \\
\hline $3.43(+15.1 \%)$ & $25 \%$ \\
\hline $2.95(-1 \%)$ & $30 \%$ \\
\hline $2.86(-4.03 \%)$ & $35 \%$ \\
\hline $2.66(-10.74 \%)$ & $40 \%$ \\
\hline $2.38(-20.13 \%)$ & $45 \%$ \\
\hline $2.35(-21.14 \%)$ & $50 \%$ \\
\hline
\end{tabular}

\section{Conclusion}

- $\quad$ Coarse aggregate can be substituted by WG until $25 \%$ proportion, without decreasing in compressive and tensile strengths.

- $\quad 25 \%$ WG replacement indicated an around $14 \%$ increase in compressive strength. 
- $25 \%$ waste glass replacement indicated an around15 \% increase in tensile strength.

- With growing the substitution proportion of coarse WG, the water absorption ratio decreases.

- $\quad$ The best dose of coarse waste glass substitution is $25 \%$.

- The color of concrete does not change during utilizing coarse WG.

- $\quad$ The density lessened by around $4 \%$ during using $50 \%$ coarse WG.

- The workability lessened by raising the WG content.

\section{Acknowledgement}

None.

\section{Conflict of Interest}

No conflict of interest.

\section{References}

1. Eme DB, Ekwulo EO (2018) Effect Of Crushed Glass As Coarse Aggregate For Concrete Pavement. American Journal of Engineering Research (AJER) 7(1): 336-345.

2. Olomo Rachael O, Alao Matthew O, Popoola Oyinade C, Ogundare Damilola A (2019) Partial Replacement of Coarse Aggregate with Waste Glass in Concrete Production. Journal of Mechanical and Civil Engineering (IOSR-JMCE) 16(3): 63-69.

3. Muzamil Liaqat, Mudasir Liaquat Shah, Mirza Aamir Baig (2018) Effect of Waste Glass as Partial Replacement for Coarse Aggregate in Concrete. International Journal of Technical Innovation in Modern Engineering \& Science (IJTIMES) 4(6).

4. Kumar Animesh, Jeet Tiwari, Kapil Soni (2017) Partial Replacement of Fine Aggregate \& Coarse Aggregate by Waste Glass Powder \& Coconut Shell. International Research Journal of Engineering and Technology (IRJET) 4(10).

5. Ishan Srivastava, Sukhvinder Singh Sehmi, Dushyant Gupta, Kumar Shivam, Jhalki Bharadwaj (2017) Partial Replacement of Fine Aggregates with Waste Glass. International Journal of Advance Research Ideas and Innovations in Technology 3(4).

6. Zainab Z Ismail, Enas A AL-Hashmi (2009) Recycling of waste glass as a partial replacement for fine aggregate in concrete. Waste Management 29: 655-659.

7. Shayan A, Xu A (2006) Performance of glass powder as a pozzolanic material in concrete: a field trial on concrete slabs. Cement and Concrete Research 36(Compendex): 457-68.

8. Esraa Emam Ali, Sherif H Al-Tersawy (2012) Recycled glass as a partial replacement for fine aggregate in self compacting concrete. Construction and Building Materials 35: 785-791.

9. Aseel B AL-Zubaid, Kadum Muttar, Shabeeb Aynoor, Ibrahim Ali (2017) Study The Effect of Recycled Glass on The Mechanical Properties of Green Concrete. Energy Procedia 119: 680-692.

10. Topçu I, Canbaz M (2004) Properties of concrete containing waste glass. Cement and Concrete Research 34: 267-274.

11. Fengchi Wang, Xingming Wu, Chao Guo, Wen Song (2018) Experimental Study on Bond Strength of Deformed Steel Bars in Recycled Glass Aggregate Concrete. KSCE Journal of Civil Engineering 22(9): 34093418.

12. Xin Yu, Zhong Tao, Tian Yi Song, Zhu Pan (2016) Performance of concrete made with steel slag and waste glass. Construction and Building Materials 114: 737-746.
13. Ali A Aliabdo, Abd Elmoaty M Abd Elmoaty, Ahmed Y Aboshama (2016) Utilization of waste glass powder in the production of cement and concrete. Construction and Building Materials 124: 866-877.

14. Muzamil Liaqat, Mudasir Liaquat Shah, Mirza Aamir Baig (2018) Effect of Waste Glass as Partial Replacement for Coarse Aggregate in Concrete. International Journal of Technical Innovation in Modern Engineering \& Science (IJTIMES) 4(6).

15. G Vijayakumar, H Vishaliny, D Govindarajulu (2013) Studies on Glass Powder as Partial Replacement of Cement in Concrete Production. International Journal of Emerging Technology and Advanced Engineering 3(2).

16. V Corinaldesi, G Gnappi, G Moriconi, A Montenero (2005) Reuse of ground waste glass as aggregate for mortars. Waste Management 25(2): 197-201.

17. Vasudevan Gunalaan, Pillay Seri Ganis Kanapathy (2013) Performance of Using Waste Glass Powder in Concrete as Replacement of Cement. American Journal of Engineering Research (AJER) 2(12).

18. Diego Romero, Jacqueline James, Rodrigo Mora, Carol D Hays (2013) Study on the mechanical and environmental properties of concrete containing cathode ray tube glass aggregate. Waste Management 33(7): 1659-1666.

19. Kumarappan N (2013) Partial Replacement Cement in Concrete Using Waste Glass. International Journal of Engineering Research and Technology (IJERT) 2(10).

20. Vijayakumar G, Vishaliny H, Govindarajulu D (2013) Studies on Glass Powder as Partial Replacement of Cement in Concrete Production. International Journal of Emerging Technology and Advanced Engineering 3(2)

21.V Ducman, A Mladenovič, JS Šuput (2002) Lightweight aggregate based on waste glass and its alkali-silica reactivity. Cement and Concrete Research 32(2): 223-226.

22.IE Kısacık (2002) Using Glass in Concrete, BS Thesis, Osmangazi University, Faculty of Eng and Arch, Dept of Civil Engineering, p. 52.

23. CD Johnston (1974) Waste glass as coarse aggregate for concrete. J Test Eval 2(5): 344-350.

24.V Ducman, A Mladenovic, JS Suput (2002) Lightweight aggregate based on waste glass and its alkali - silica reactivity. Cement and Concrete Research 32: 223-226.

25. SB Park, BC Lee, JH Kim (2002) Studies on mechanical properties of concrete containing waste glass aggregate, Ninth Annual International Conference on Composites Engineering, in: D Hui (Ed.), Sponsored by International Community for Composite Engineering and College of Engineering, University of New Orleans, California, pp. 603-604.

26. C Polley, SM Cramer, RV Cruz (1998) Potential for using waste glass in Portland cement concrete. J Mater Civ Eng 10: 210-219.

27. ESS 2421/2005 - Egyptian Standard Specification, Cement - Physical and Mechanical Tests.

28. ESS 1109/2002 - Egyptian Standard Specification, Aggregate for Concrete.

29. British Standard Institution (1952) Method of testing concrete B.S.1881, BSI, London.

30. BS 12350-2 (2009) Testing of Concrete: Slump Test, British Standards Institute. London, United Kingdom.

31. ESS 1658/2006 - Egyptian Standard Specification, Testing of Concrete.

32. Vikash Agrawal, JP Singh, CR Sharma (2018) Studies of Characteristics Strength and Durability of concrete using waste glass as partial replacement of coarse aggregate. International Journal for Research in Engineering Application \& Management (IJREAM) 4(6). 